\title{
La batalla del teatro en el reinado de Carlos III (II)*
}

ANTONIO DOMínGUEZ ORTIZ

Real Academia de la Historia

En esta segunda parte del presente trabajo me propongo aportar algunos datos inéditos acerca del problema del teatro en Andalucía durante el siglo XVIII. Es tema sobre el cual existen ya algunas excelentes monografías, como es el caso, para Sevilla, del volumen de don Francisco Aguilar Piñal, ' lo cual nos autoriza a limitarnos a las indispensables referencias. Hay, en cambio, detalles curiosos y desconocidos acerca de los avatares de aquella controversia en poblaciones de importancia secundaria, que serán el núcleo fundamental de nuestra exposición.

Andalucía parecía predestinada a ser la tierra más propicia para el arte teatral por su riqueza, su complejo entramado urbano, su carácter cosmopolita y el carácter abierto y festivo de sus gentes. Así ocurrió durante el siglo XVI y comienzos del XVII; después se hizo notar en ella, quizás con más fuerza que en otras

* Continuación del artículo del mismo título en Anales de Literatura Española, núm. 2, 1983.

1 Sevilla y el teatro en el siglo XVIII. Oviedo, Servicio de publicaciones de la Universidad, 1974. 
partes, el entenebrecimiento del horizonte vital y un concepto apocalíptico del mundo favorecido por eclesiásticos más celosos que discretos, que veían pecados en las más inocentes ocasiones de diversión. Hay que decir que esos eclesiásticos estuvieron bien secundados por miembros de las oligarquías urbanas dueños de los municipios y partícipes de sus ideas. Recordemos el cierre de los teatros de Sevilla y Córdoba en 1679 y 1694 a impulsos de los padres Tirso González y Francisco Posadas, respectivamente. La prohibición se reiteró, para Sevilla y todos los pueblos de su arzobispado, en septiembre de 1731, durante la estancia de Felipe $\mathrm{V}$ en aquella capital, circunstancia que parece debería haber mitigado la dureza de dicha prohibición. Cierta relajación se advirtió en este rigor al comenzar el reinado de Carlos III; desde 1761, aunque sin autorización expresa, se toleraron representaciones de ópera italiana, despertando las mismas reprobaciones que las comedias. «Los actores y actrices, escribía el autor de un Discurso anónimo, son hombres y mujeres cuyo arte es el de agradar a los oyentes, halagar sus sentidos y excitar sus afectos. Gente por lo común de gala natural, ayudada del arte con toda la pompa consiguiente a parecer bien. Su fin principal compareciendo en la escena es despertar aquellas pasiones que forman el sujeto de su acción, sea amor, ira, ambición, venganza, etc. El amor profano es el más común asunto de sus piezas [...] Sus vestidos respiran lujo, pompa y soberbia, y los artífices procuran darles todos los atractivos que la moda sugiere ${ }^{2} . »$

Tales eran los imperdonables defectos que aquellos Zoilos encontraban en las óperas y, por supuesto, en las comedias. No se trataba sólo ni principalmente de los argumentos, puesto que no se prohibía su lectura; incluso se toleraban algunas representaciones en casas particulares. Era la seducción personal de las comediantas lo que parecía más peligroso a críticos acerbos y anquilosados que sostenían seguir en vigor la infamia legal de los comediantes y la prohibición eclesiástica de darles cristiana sepultura. Añádase a esta mentalidad retrógrada la preocupación

2 Aguilar Piñal: Historia de Sevilla. Siglo XVIII, pp. 271-272. Volumen VI de la Historia de Sevilla publicada por la Universidad, 1982. 
de la oligarquía por no disminuir la capacidad de explotación de la fuerza de trabajo del pueblo, factor este que influyó también en la prohibición de otras diversiones a las que nada había que objetar desde el punto de vista moral, como las corridas de toros, proscritas en 1785 y con más vigor y generalidad en $1804^{3}$, y las mesas de trucos (billares), prohibidas en 1755 y autorizadas por Carlos III «para desahogo de las clases distinguidas y honestas».

Estos motivos eran generales a toda España. Si en Andalucía la «batalla del teatro» adquirió más fuerza, si las prohibiciones se hicieron sentir con más rigor quizás fue porque en el siglo XVIII, sobre todo en su tercio final, la oposición entre renovadores y tradicionales fue más viva en aquella región, la más vital de España en el terreno económico y también en el intelectual. No olvidemos que si en Andalucía vivieron la totalidad o parte importante de sus carreras hombres como Olavide, Blanco White, Forner, Jovellanos, Marchena, Trigueros, Lista..., también fue patria o escenario de las actividades de reaccionarios tan conspicuos como fray Diego de Cádiz, fanático adversario de los espectáculos teatrales, don Pedro de Castro, defensor de la tortura judicial, el padre Ceballos y el Filósofo Rancio.

El cabildo secular de Sevilla no era menos opuesto a las representaciones teatrales que las autoridades eclesiásticas; cuando a principios de 1767 el empresario de la compañía que actuaba en el vecino pueblo de San Juan de Aznalfarache pidió autorización para establecerse de modo permanente en Sevilla, el informe que redactó a petición del conde de Aranda fue totalmente desfavorable. El de Campomanes, por el contrario, argüía que «si el mal está en las obras dramáticas, mayor daño pueden causar leídas, pues se introducen en los claustros y está franca su lectura no sólo a los seculares sino al clero [...] Si no tenemos reparo en que se lean tampoco le puede haber en la representación, porque ésta se hace a vista de las Justicia, cuyo oficio es arreglar los teatros y castigar toda acción indecente. Las comedias contra las que declamaron los Santos Padres eran las que contenían ritos gentíli-

Novísima Recopilación, libro VII, título 33, leyes 6 y 7 . 
cos. Las de santos y los autos sacramentales se han prohibido justísimamente por Su Majestad [...] La diversión pública en las grandes ciudades es una de las atenciones primeras de un gobierno bien organizado, porque la nobleza y gentes acomodadas necesitan recreaciones honestas para evitar los males de la ociosidad [...] Hay cosas que mejorar en el teatro español, haciendo que el drama haga ridículos los vicios y haga brillar las buenas costumbres, guardándose las unidades de acción, tiempo y lugar porque no se vean las monstruosidades inverosímiles que reinan en las malas piezas de esta naturaleza». En consecuencia proponía que se levantara la prohibición de representar en Sevilla, como así se acordó por R.O. de 12 de junio de $1767^{4}$. Apenas tres meses después fue nombrado asistente de Sevilla el peruano don Pablo de Olavide, en quien Campomanes tuvo el más entusiasta de los colaboradores en su intento de restaurar el arte de Talía. No sólo admitió la ópera y comedias sino que acometió la construcción de un grandioso teatro que hubiera sido a la vez escuela de arte dramático.

A la vez que secundaba los deseos de Campomanes en punto al teatro, Olavide halagaba al conde de Aranda organizando un baile de máscaras en el carnaval de 1768; por descontado, esta diversión, cara al magnate aragonés, no suscitó menor reprobación; incluso llegó al Tribunal de la Inquisición hispalense una delación firmada por un carmelita, porque en el reglamento de la función se decía que «esta diversión de la máscara es honesta por sí misma». Este detalle no tiene nada de sorprendente; lo que demuestra que los partidarios de las novedades se movían en la cuerda floja es que, habiendo llegado a conocimiento de Carlos III esta delación, «y que la expresión referida ha causado bastante rumor y aun escándalo», ordenó a Olavide por medio del ministro Roda que se recogieran todos los ejemplares del citado reglamento ${ }^{5}$.

4 A.H.N. Consejos, 1.042.

5 A.H.N. Inquisición, 3.046, carta de 21 de enero de 1768. 
Los bailes de máscaras no se repitieron. En cambio, el teatro gozó en Sevilla de unos anos de prosperidad. Frente a la sorda oposición del cabildo secular Olavide tenía el apoyo de algunos eclesiásticos, incluyendo el arzobispo, cardenal Solís, y a su familiar Cándido María Trigueros, quien, entre otras producciones, hizo una adaptación del Tartufo. Representáronse también la Alzira y otras obras de Voltaire bajo el velo del anónimo. Unos doce años duró esta etapa de prosperidad excepcional. En las citadas obras de Aguilar Piñal y Defourneaux encontrará el lector curioso amplios detalles de la ruina total del teatro sevillano, consecutiva a la de Olavide, procesado, como es sabido, por la Inquisición. Una de las proposiciones denunciadas era la siguiente: «Las buenas comedias son mejor escuela de moral que los sermones». Las representaciones fueron suspendidas de orden superior en 30 de marzo de 1779 y el teatro, ruinoso, acabó siendo demolido ${ }^{6}$. A partir de 1795 aflojó algo el rigor y se reanudaron, en tono menor, las representaciones hasta la invasión francesa.

En algunas de las más populosas villas del reino de Sevilla diversas compañías teatrales aprovecharon el clima de tolerancia que reinaba desde 1767 para efectuar representaciones en teatros improvisados. Tenemos huellas documentales de algunas de ellas, por ejemplo la que, dirigida por el autor Rafael de Solís, actuó en Osuna. Como no había teatro alquiló a Juan A. Estévez una casa, en la cual el dueño realizó las obras de adaptación necesarias, lo que denota confianza en la continuidad de las representaciones. No debía contar con la huéspeda, en este caso el corregidor ${ }^{7}$, que alegó quejas por el ruido y ordenó a los cómicos que buscaran otro local o se marcharan del pueblo. Elevada la cuestión al Consejo de Castilla, autorizó las representaciones con ciertas condiciones, entre ellas que hubiera la debida separación de sexos en el público. Las autoridades de Osuna dispusieron que las representaciones se dieran de forma alternativa, un día para

\footnotetext{
Aguilar Piñal, obras citadas. M. Defourneaux: Pablo de Olavide. París, P.U.F. 1959.

Lo era D. José Sánchez Jurado; en realidad no era corregidor sino alcalde mayor, porque Osuna era villa de señorío.
} 
hombres y otro para mujeres. El dueño del local protestó del perjuicio que se le seguiría a la compañía y a él mismo, y proponía trazar una raya en el suelo del corral que dividiera los dos sexos. A trancas y barrancas se siguieron representando comedias hasta que en 1769 vuelven las protestas, centradas en dos aspectos: insuficiencia del edificio y daños a la moral pública. Para el primero puede servir de ilustración una visita hecha en 8 de agosto del citado año; los delegádos del cabildo, acompañados de los peritos, giraron una visita de inspección al corral de comedias, situado en la calle de San Pedro: «... Hay un colgadizo cubierto de tierra, tabicado por el testero, al lado del tablado, bajo el cual hay un pozo [...] Hay una división hecha con vigas hincadas en el suelo y otras a lo largo. Hay un lugar descubierto con siete cuartos, y frente a él una puerta que da al jardín de una caballeriza, sin llave, cubierta por el tablado hecho para la representación. Por aquí se va a unos cuartos altos, estando este patio cercado de tablas». Si la imagen material del teatro en Osuna era de lo más sórdido, no resultaba mejor parado en lo moral de las declaraciones que el alcalde mayor tomó a don Francisco Barahona, el cura más viejo de la localidad; bajo juramento declaró que las representaciones habían sido "muy escandalosas y perjudiciales, en gran ofensa de Dios, faltando los farsantes a la modestia en trajes y meneos, por lo que debe sacarse del pueblo este contagio». Otros curas informaron en el mismo sentido, así como de que la separación interior de sexos no tenía eficacia suficiente para evitar escándalos. Por la oposición de las autoridades o por cansancio del público la compañía terminó por marcharse a Marchena ${ }^{8}$. En 1781 el rey sancionó el acuerdo que hizo la municipalidad de Osuna, como la de muchas otras villas andaluzas, de no admitir comedias.

Excepción única en Andalucía fue Cádiz, donde las autoridades nunca pensaron en prohibir el teatro, pensando en su numerosa, culta y cosmopolita población. No sólo hubo un teatro sino dos y en ciertos momentos tres, representándose comedias espa- 
ñolas y francesas y óperas italianas. Como muestra de la tolerencia reinante se cita la representación de tragedias de Voltaire. Sin entrar en esta cuestión, ya estudiada por Defourneaux ${ }^{9}$ y Didier Ozanam ${ }^{10}$, me limitaré a señalar que tampoco faltaban en Cádiz detractores de los espectáculos teatrales en general. A comienzos del año 1766 el Consejo pidió informe al gobernador de Cádiz acerca de las denuncias formuladas por una persona que en el expediente se expresa contra las óperas que en aquella ciudad se representaban. A juzgar por las respuestas, los reparos eran de orden moral. El gobernador, don José de Sentmanat, negó que hubiera motivos de escándalo, porque la espléndida iluminación y la estricta vigilancia lo hacían imposible. Con este motivo suministra algunas precisiones de interés acerca de los comienzos de las representaciones operísticas en Cádiz; comenzaron con sesiones musicales en una morada particular; luego se habilitó para teatro un juego de pelota. No era cierto que se estuviera planeando construir un edificio de nueva planta. La mayoría de los asistentes eran extranjeros, hasta el punto de que de los catorce o quince que abonaban los palcos por temporadas sólo dos eran españoles. En cambio el obipso, fray Tomás del Valle, opinó en el mismo sentido que el denunciante. Según su criterio, las óperas italianas eran aún más peligrosas que las comedias para la salud espiritual y temporal de los espectadores por el dispendio de caudales y la desenvoltura de las bailarinas. «Es tal el atractivo de las actoras, decía, que arrastra no sólo a los jóvenes sino también a los ancianos, advirtiéndose muchos matrimonios en inquietudes por la inconsideración [sic] de las mujeres, que careciendo aun de lo preciso fatigan a sus maridos por las óperas. Se nota que muchos acaudalados disipan sus haberes en estos pasatiempos y que varias familias pobres procuran conseguirlos por ilícitos medios». Prevaleció, sin embargo, la opinión del gobernador y las representaciones continuaron, aunque no por mucho tiempo, pues en 1783 la propietaria del Coliseo pedía permiso para demo-

9 L'Inquisition espagnole et les livres francais au XVIII siècle. París, P. U. F., 1963, pp. 150151 .

10 «Le théâtre français de Cadix au XVIII siècle (1769-1779)», Mélanges de la Casa de Velazquez, X (1974), 217 y sig. 
lerlo y destinar el local a juegos de bocha y billar, porque hacía largo tiempo que no había óperas y las comedias tenían edificio propio ${ }^{11}$.

Como queda dicho, Cádiz fue un caso excepcional, puesto que, aunque disminuidas, las representaciones escénicas salvaron el tremendo bache de finales del XVIII. Sobre las vicisitudes del teatro en Jerez hay un buen estudio de don Manuel Ruiz Lagos, al que remitimos ${ }^{12}$. Limitémonos a decir, sintetizando su relato, que tuvo teatros permanentes desde fines del siglo XVI y que en el XVIII tropezó con la oposición de la Iglesia, encarnada en los arzobispos Espínola y Palafox, que lograron su extinción ${ }^{13}$. El Ayuntamiento mantuvo una actitud indecisa, tan pronto en favor como en contra de las representaciones. La ópera italiana se introdujo, antes que las comedias, a mediados del siglo XVIII. El Ayuntamiento redactó unas ordenanzas en 1772 que tuvieron escasa vigencia; poco después comenzó la formidable ofensiva acaudillada por fray Diego de Cádiz y secundada por los obispos andaluces, que condujo a la extinción.

Muy características de la mentalidad de la época son las vicisitudes por las que atravesó el teatro en la Isla de León (hoy San Fernando) población que, situada en la base del largo istmo arenoso en cuyo extremo se halla Cádiz, albergaba, entre otras instituciones, el observatorio astronómico, dotado de magnífica biblioteca, la única de carácter científico que puede decirse estaba al día en la nación. Por la cantidad y calidad de sus habitantes parecía muy indicado para mantener representaciones teatrales, y en efecto, tuvo un teatro que entre 1770 y 1800 funcionó en las condiciones de que nos informa un expediente conservado en el Archivo Histórico Nacional ${ }^{14}$, y que concluyó de una manera sorprendente.

11 A.G.S. Gracia y Justicia, 993. Quien desee hacer un estudio del teatro gaditano en esta época deberá tener también en cuenta las noticias contenidas en el expediente 25 del legajo 823 (A.H.N.).

12 Controversias en torno a la licitud de las comedias en la ciudad de Jerez de la Frontera 11520 1825). Publicaciones del Centro de Estudios Históricos Jerezanos, $n .^{\circ} 25,1964$.

13 Jerez formaba parte entonces del territorio del arzobispado de Sevilla.

14 A.H.N. Consejos, 1.305, expdte. 16. 
El citado expediente se abre con un memorial dirigido al Consejo de Castilla por don Diego Duarte en 28 de mayo de 1789 en el que expresa que en 1770 don Juan Hercq, del comercio de Cádiz, obtuvo licencia para construir en la Isla de León una casa de comedias que poco después tuvo que cerrar y vender porque el edificio, mal construido, quedó en estado ruinoso. En 1783 actuó en la población una compañía teatral en un teatro de madera que ellos mismos levantaron. Las representaciones cesaron en breve por haber ganado en marzo del 84 real cédula el señor obispo ${ }^{15}$ para que se suspendieran en todo el obispado excepto la capital. Ahora la villa ha crecido a más de diez mil vecinos (sigue diciendo Duarte) que carecen de paseos y otras diversiones, por lo que sería muy oportuno reanudar las representaciones. Para dar más peso a su solicitud ofrecía contribuir con cuatro maravedises por entrada al hospital de San José.

En vista de los informes favorables del Ayuntamiento y del fiscal del Consejo, y a pesar de la oposición del obispo, que se oponía sin alegar razones concretas, el Consejo de Castilla autorizó a Duarte para edificar un teatro, encargando a las autoridades locales que evitaran todo motivo de queja y escándalo, gobernándose por las reglas establecidas para Madrid y Cádiz. Carlos III, tan hostil al teatro en los últimos años de su vida, había muerto en diciembre de 1788. Es probable que estos hechos se relacionen con el talante más liberal que en este punto adoptó Carlos IV. Pero lo sorprendente, y lo que pinta el estado de espíritu de un pueblo y la mala conciencia que en el fondo tenían los empresarios teatrales es el memorial que Josef Delgado Duarte, sobrino de don Diego y heredero del teatro, dirigió al Consejo en 14 de noviembre del año 1800 , es decir, en una época en la que toda Andalucía era víctima del cólera morbo. Dice que el teatro «funcionó hasta hace muy poco tiempo antes de la epidemia que ha afligido a estos pueblos; en cuyo discurso, el representante ha conocido que la diversión causa alguna ruina espiritual, y como no quiere lucro a costa de su conciencia, e indirectamente se considera causante de las ofensas que se puedan cometer contra am-

15 Lo era entonces D. José Escalzo y Miguel. 
bas majestades», avisa al Consejo que renuncia a seguir arrendando la casa de comedias.

Advertimos también el choque de mentalidades típico de los finales del antiguo régimen en otra ciudad del mismo entorno que la anterior; por su situación en la bahía de Cádiz, la ciudad del Puerto de Santa María se benefició del comercio con América, como todavía hoy demuestran las numerosas casas blasonadas, residencia de ricos mercaderes. El paso de la ciudad al dominio directo de la Corona en 1729 le quitó el poderoso patrocinio de los duques de Medinaceli, pero éstos siguieron teniendo allí cuantiosas propiedades, y también siguió siendo puerto militar a pesar de que las galeras se concentraron cada vez más en la base de Cartagena. Dotada de amplia burguesía mercantil, militares, marinos y renombrados establecimientos de enseñanza, entre ellos el colegio de jesuitas, parece que debió de haber tenido una actividad teatral intensa; sin embargo, el muy documentado y erudito historiador del Puerto, don Hipólito Sancho, nada dice ${ }^{16}$ y la documentación es muda hasta el año 1780, en el que la municipalidad, a instancias de fray Diego de Cádiz, acordó no admitir comedias ni óperas. El gobernador militar, conde de O'Reilly, se adhirió a la petición, y el rey la sancionó el año siguiente ${ }^{17}$.

Sin embargo, en junio de 1789, un vecino, José de la Flor, se dirigió al Ayuntamiento en solicitud de que se le permitiera labrar un corral de comedias. En realidad, lo que pretendía era que se convalidase un hecho consumado, porque el edificio ya estaba hecho con licencia del corregidor. En el expediente se inserta la nómina de la compañía de Flor y un certificado del prior de la comunidad de San Juan de Dios de haber percibido, en los cuatro meses que había estado abierto el teatro, tres mil reales, a cuarto por entrada (el precio de la entrada ordinaria era de dos reales, y uno más por el banco de la cazuela). Flor apoyaba sus argumentos alegando que con frecuencia habían asistido diversas autoridades a las funciones. ¿Por qué no se opuso el Ayuntamiento an-

16 Historia del Puerto de Santa María. Cádiz, Escelicer, 1943.

17 A.H.N. Consejos, 1.315-7. Este es el expediente básico del que proceden la mayoría de las noticias que damos a continuación. 
tes de que hubiera gastado de siete a ocho mil pesos en la construcción del teatro?

Los argumentos de Flor no hicieron mella en los cabildantes que, en agosto del mismo año, se ratificaron en la prohibición, aduciendo razones de tipo más sociológico que moral: los portuenses no necesitaban representaciones teatrales porque tenían para su recreo hermosos paseos, dos ferias anuales, diez corridas de toros y otras diversiones; además, el pueblo era pobre y aficionado al lujo; los artesanos querían igualarse a los poderosos y los jóvenes de ambos sexos estaban «dispuestos a toda diversión con abandono de sus ocupaciones». El empresario encontró apoyo en la clase mercantil; 39 comerciantes elevaron a Madrid una exposición refutando los argumentos del cabildo; la abundancia de diversiones era aparente; las ferias sólo duraban quince días, y los toros se corrían en esas mismas fechas. Aunque el fiscal, en 12 de enero de 1790, opinaba que debían permitirse las representaciones por las mismas razones que en la Isla de León, el Consejo dictó auto prohibiéndolas pero la situación en el Puerto siguió siendo confusa; el Ayuntamiento reiteró la prohibición; Flor, en febrero de 1791, ofreció tres cuartos por entrada para las obras de la carretera. En 9 de octubre de 1792 varios regidores hacían historia de la cuestión: con el pretexto de máquina real y títeres, espectáculos no prohibidos, habían vuelto los bailes, los entremeses y, finalmente, las comedias, contra los acuerdos de la ciudad, con gran daño de ella por la libertad de costumbres de los cómicos. En efecto, figura en el expediente una lista de comedias programadas para el mes de octubre de aquel año ${ }^{18}$.

18 He aquí la lista en cuestión:

Los días 1 y 2 se representaría La dama duende.

3,4 y 5, El príncipe prodigioso.

6 y 7 , Carlos V sobre Dura.

8 y 9, El criado de dos amos.

10 y 11, La amazona de Scitia.

12 y 13, Los Esforcias de Milán.

El día 14, Luis $X I V$ con iluminación y besamanos de gala entera.

El 15 y 16, La Gabriela, tragedia. Besamanos de media gala.

El 17 y 18, El amo criado.

El 19, El príncipe perseguido. 
Llevado de nuevo el asunto al Consejo de Castilla, un fiscal que no puedo identificar por su rúbrica, pero que no era el mismo que tres anos antes opinaba en sentido favorable a las representaciones, manifestaba en 3 de abril de 1793 que el corregidor había desobedecido el auto dado por el Consejo en 1790, por lo que las representaciones debían cesar inmediatamente. Pero el empresario, que, sin duda tenía comprometidos gran parte de sus ahorros, no se daba por vencido, e insistía en sus pretensiones y argumentos. El Puerto era ciudad de 25.000 habitantes, entre los que había «sugetos de la mayor distinción, sin contar los que iban en tránsito a Cádiz»; adjuntaba certificación de las cantidades entregadas al hospital de San Juan de Dios y alegaba que la Audiencia de Sevilla le había autorizado para que se representaran tonadillas, sainetes y todo lo que no fuera comedias. Ante esta representación, la Fiscalía del Consejo evidenció una vez más lo débil y contradictorio de su postura; en un dictamen de 5 de octubre de 1793 decía que la prohibición general dictada en 1784 para toda Andalucía tuvo desde el principio la excepción de Cádiz; luego se levantó para Granada y la Isla de León, y había instancia pendiente para que se permitieran comedias en Sevilla. No se atrevía a pedir la revocación del auto que las prohibía en el Puerto y sugería que antes de tomar una decisión se pidieran informes a la audiencia de Sevilla y al gobernador de Cádiz. Este informó a favor; también los fiscales de Sevilla, don Juan Francisco de Cáceres y don Juan Pablo Forner; sin embargo, la Audiencia dictaminó en favor de la prohibición, motivando una protesta de los fiscales en la que resuenan los bien conocidos argumentos de Forner en pro de las diversiones públicas: «... Las circunstancias presentes que tienen envuelta la nación en una guerra de tanto interés qual no se ha conocido nunca, suelen ser-

El 20 y 21, Cristóbal Colón.

El 22 y 23, Mentir y mudarse a un tiempo.

El 24 y 25, El Demofonte.

El 26, El delincuente honrado.

El 27 y 28, El pleito de Hemán Cortés con Pedro de Narváez.

El 29, El Dómine Lucas.

El 30, El capitán Belisario.

El 31, La gitanilla de Madrid. 
vir de pretexto para negarse al establecimiento de aquellos desahogos que la buena política opone diestramente al ocio y a la corrupción de las diversiones obscenas y clandestinas. Ciertamente, en los tiempos calamitosos conviene mucho orar e implorar el auxilio del Omnipotente, pero la práctica del mundo enseña que los hombres en todas las situaciones son los mismos, que en los tiempos calamitosos crecen los vicios por lo mismo que crecen las necesidades, y la política prueba que al vulgo se le sugeta más distrayéndole que afligiéndole. Es difícil que la parte más activa del pueblo, que es la juventud, quiera concurrir de continuo a los templos, aunque se le quiten todas las proporciones para divertirse, y es más que probable que recurra a la diversiones aun quando se halle envuelto en la calamidad. La razón de esto es que los templos entristecen y los espectáculos alegran [...] Un pueblo numeroso donde se reúnen gentes de todas partes al cebo de la negociación exige más que otro alguno aquellos establecimientos que, facilitando una distracción halagüeña, impiden la formación de pandillas y concurrencias privadas donde se agiten los negocios públicos y la situación de las cosas [...] Ni aparta a los fiscales de su sentir el constarles que la ciudad del Puerto ha obtenido facultad para celebrar corridas de toros ${ }^{19}$. Siempre han creído que este feroz espectáculo no puede ni debe entrar en competencias con los cultos regocijos del teatro».

Natalio Ortiz, representante de José de la Flor, también trataba de explotar para su causa el terror pánico que los sucesos de Francia habían despertado en el gobierno. «Preséntense al público, decía, en piezas bien escogidas, los engaños, ardides y violencias con que conspiraron al despotismo bajo el velo de la libertad, y declámense los estragos que han sucedido a semejantes novedades y turbaciones del Gobierno». Los antagonistas del teatro pretenden que las personas, después de sus tareas, se retiren a «la melancólica lobreguez de las iglesias», pero lo cierto es que se ve a los ciudadanos de diversas clases y naciones «metidos en los ca-

19 Las fiestas de toros de muerte se prohibieron por pragmática de 9 de noviembre de 1785 , reiterada en 20 de diciembre de 1804 (Novísima Recopilación, libro VII, título XXXIII, leyes 6 y 7). 
fees, en casas de corrupción y en otros sitios criticando las cosas del Gobierno y denostando a los ministros.»

El intento de salvar el teatro del Puerto con argumentos políticos no tuvo mejores consecuencias que los anteriores. El Ayuntamiento seguía dominado por sus adversarios. Unos regidores, en julio de 1794, negaban que el vecindario de la ciudad fuera tan alto como se decía. «Por certificaciones de los párrocos hay 14.091 almas de comunión ${ }^{20}$ y aunque se aumentara una cuarta parte de párvulos, religiosos y militares, ascendería a 16.714.» La pobreza de la ciudad se deduce de la emigración, de las limosnas que da la Hermandad de la Caridad a innumerables pobres y «del

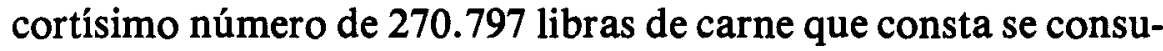
men al año». La falta de recursos era el motivo de que nadie hubiera tomado la contrata de las corridas de toros; pero hay cafés, billares, naipes lícitos, bochas y un reñidero de gallos. Y luego, el argumento supremo, el argumento moral: las cómicas ganan poco. Si gastan lujo es casi indispensable que se prostituyan. «Si San Juan de Dios hubiera previsto de dónde salen las limosnas para su hospital hubiera desistido de su fundación.» No eran los frailes del mismo parecer; todavía intentaron seguir luchando pero en balde. El fiscal del Consejo de Castilla (no confundir con los fiscales de la Audiencia de Sevilla) opinó que debía mantenerse la prohibición de las comedias. El Consejo dictó auto en este sentido el 1 de diciembre de 1794 y el teatro portuense de la calle Misericordia se cerró, aunque parece que tampoco esta vez de modo definitivo, ya que existe una nueva instancia de la ciudad el año 1800 solicitando la aprobación del voto de extinción del teatro para aplacar la ira de Dios en la terrible epidemia que padecía ${ }^{21}$. Es un buen ejemplo de cómo el régimen absoluto no era incompatible con las tergiversaciones y las resistencias pasivas.

Parece que el momento óptimo para la resurrección del arte de Talía en tierras andaluzas, es decir, los años siguientes al del

20 Expresión un tanto vaga que se refería a los mayores de siete años, tope que podía ampliarse a los diez e incluso a los catorce.

21 A.H.N. Consejos, 1.992-7. 
1767 , se hizo notar incluso en pueblos pequeños como eran los de Villaluenga, Ubrique, Grazalema y Benaocaz, en lo más intrincado de las serranías sevillano-gaditanas. Así se desprende del memorial conjunto elevado al Consejo por dichos municipios en 23 de septiembre de 1783 para que no se permitieran comedias ni óperas (!), «y para no ser inquietados por las compañías cómicas que suelen andar sueltas de pueblo en pueblo con despachos del Juez Protector para que no se les impida el uso, y aun que se les suministren bagages para los tránsitos, como tampoco por particulares vecinos, so color de ser los productos que sacan para obras pías ${ }^{22}$.» Sin duda, éste fue también el caso de otras muchas poblaciones pequeñas, en las que el choque ideológico, a propósito de las representaciones teatrales, se manifestó con variable intensidad. En este punto sólo podemos deplorar las lagunas de nuestra información.

Algo más completa (o menos incompleta) es la que tenemos sobre Antequera, que en el siglo XVIII era una de las ciudades más importantes de Andalucía; los productos de su amplia vega estaban incrementados por algunas industrias y por los beneficios derivados de su posición en la ruta que unía Cádiz con Granada y Madrid. Siempre fue punto de mucho comercio, bastante contrabando, sólidas fortunas y no poca población flotante, circunstancias todas que parecían favorecer el desarrollo de la afición teatral. Tenemos pruebas de que las iniciativas de Campomanes y Aranda no cayeron en el vacío. En 1770 el regidor perpetuo don José Vicente de Casarola Paniagua ofreció un edificio de su propiedad de $28 \times 16$ varas al Ayuntamiento para que lo dedicase a representaciones teatrales. Suponemos que lo haría movido por la idea del lucro, aunque la oferta iba envuelta en la fraseología propia del momento: se proponía "concurrir a los deseos del gobierno y obviar las nocivas consecuencias de la total ociosidad con las decentes diversiones de representaciones cómicas, óperas de máscara, música y volatines». A cambio de la cesión del local pedía una participación en los ingresos y la prohibición de otros espectáculos que le hicieran competencia. 
Obtenido el apoyo del corregidor, el cabildo secular tomó el siguiente acuerdo: «La ciudad, que desde el día 6 de marzo de 1769 quedó enterada de la orden de Su Majestad y Srs. del Real Consejo para no sólo deber permitir las diversiones de comedias sino proponer medios con que hacer construir teatros para ellas, aunque dio traslado al caballero Procurador Personero no pudo lograrse el buen efecto por no haber sobrante de Propios [...] celebra hoy la coyuntura con que se ha brindado a sacarla de este cuydado el eficaz celo de D. José Vicente de Casarola...», al cual expresa las gracias por esta oferta y la de unos aposentos en el teatro que habia de construirse.

Un jarro de agua fría fue el «no ha lugar» con que respondió la sala de gobierno del Consejo en 6 de febrero de 1771. La causa de la negativa era doble; de un lado, la pretensión de Casarola de admitir y despedir las compañías a su arbitrio; de otra, la mezquindad del edificio que ofrecía. "Luego que la ciudad tenga proporción para construir una casa teatro decente, capaz y correspondiente a su población, quedándole libre su uso, lo haga presente al Consejo».

El expediente que utilizamos no es lo bastante completo como para reconstruir todas las incidencias; sería ntcesaria una investigación en las actas capitulares. Sin embargo, la línea principal de los acontecimientos puede seguirse. La municipalidad no labró un teatro pero durante varios años se dieron representaciones en una finca del referido Casarola que no debía de ser la misma antes citada sino otra más amplia, pues se le dan unas dimensiones de cincuenta varas en cuadro. Sin duda necesitó grandes obras de adaptación porque había servido antes de almona de jabón. Probablemente, a estas obras de adaptación es a lo que el hijo de Casarola llamó más tarde «la obra del teatro» que había realizado su padre.

Hasta allí llegó la propaganda antiteatral de fray Diego de Cádiz, motivando una prohibición circunstancial en 1781. Volvieron a celebrarse algunas funciones pero el ambiente se iba espesando, y se concretó en la petición enviada al Consejo en 18 de abril de 1784 de hacer firme y perpetua la prohibición. Es posible 
que el motivo desencadenante fuera la solicitud de una compañía que se dirigió al corregidor para que se le permitiese dar unas funciones; el corregidor se lavó las manos en el asunto y lo transmitió a la municipaldad, la cual informó que «semejantes diversiones no son adaptables al público, lo que se acreditó con las que se executaron el año pasado, que pasados algunos días en que la novedad juntó algunas gentes, a poco tuvieron que retirarse por no concurrir las precisas para sacar los costos, y esto en tiempo que estaba el pan a cuatro cuartos [...] el cual en el día está a ocho.»

Pasan los años, y bajo Carlos IV se mitiga el rigorismo antiteatral. En febrero de 1797 don Diego Casarola expone al Consejo de Castilla que, a pesar de la prohibición dictada en 1784 en Málaga, se había construido una casa de comedias donde se estaba representando y por ello pedía licencia para «continuar y perfeccionar cierto coliseo de comedias que en virtud de contrata había principiado a construir su padre.» El Consejo pidió los informes de costumbre. El de la ciudad fue favorable. El del corregidor merece extractarse a pesar de lo ampuloso de su estilo: «... A los célebres dragmas [sic] de Calderón, Moreto, Candamo y otros jamás se les podrá negar el singular mérito de sus autores; pero [...] tienen cierta inducción a las pasiones que quizás serán peligros remotos para los incautos, y con este motivo han durado los clamores de los rigoristas. Mas no han llegado a decir que el Gobierno tenga obligación de prohibirlos. Por el contrario, todos los políticos convienen en que es uno de sus principales deberes proporcionar a los pueblos recreaciones [...] Algunas personas querrían que los hombres, sobre ser impecables, practicasen sin intermisión las virtudes, pero esto no es para todos, y aun los que viven una vida espiritual necesitan de la Eutrapelia.» Se refiere a los «votos imprudentes» hechos por diversas poblaciones y concluye en sentido favorable a la concesión de la licencia solicitada. Tanta retórica no bastó a convencer al fiscal: «Aunque no existieran tales prohibiciones, bastan las prerrogativas que solicita el don Diego y ha acordado la ciudad en su favor para que se le deniegue, y prevéngase a la ciudad que, siendo conveniente edificar teatro, proponga los medios de executarlo». 
La respuesta del fiscal es de 30 de abril de 1798. Antequera no debió de insistir y en 12 de marzo de 1803 una escueta nota puso punto final a la cuestión: «Sobreséase este expediente» ${ }^{23}$.

No nos detendremos en estudiar las vicisitudes del teatro en Córdoba, conocidas ya en sus líneas generales por las obras de Rafael Ramírez de Arellano y L. M. Ramírez Casas-Deza. Limitémonos a recordar que, prohibidas las representaciones en 1694 por acuerdo municipal que obtuvo, no sin trabajo, el famoso dominico Francisco Posadas, cesaron las representaciones hasta que, al calor del nuevo clima creado por Campomanes, se reanudaron en un teatro de madera, pero en 24 de febrero de 1784, el rey, atendiendo a las súplicas del obispo don Baltasar de Yusta, las prohibió en todo aquel obispado. La solicitud hecha en 1799 por el empresario Casimiro Montero para reanudarlas tropezó con el doble veto municipal y episcopal. Resulta instructivo ver como en el informe del obispo Ayestarán y Landa se mezclan las consideraciones sociopolíticas con las religiosas y morales. "Las actoras se ven en trajes que más sirven para manifestar desnudez y modelar las carnes que para cubrirlas con decencia; practican acciones que no son del carácter ni de la representación, pero sí inflaman al auditorio, buscando aplauso. Miran, no como deben, y sí buscan siempre a los conservadores de su disolución. Equivócanse de propósito, y la equivocación no es otra cosa que un dicho, palabra o período torpísimo; ejecutan movimientos indecentes y obscenos [...] Para mayor desgracia, las más de nuestras comedias están tejidas sobre un suceso de amor...».

Y por otra parte, las comedias «siempre presentan en las tablas príncipes débiles, militares altaneros y capitanes que no tienen más moral que la de su espada; grandes señores sin otra virtud que la de satisfacer sus antojos. Un padre de familia burlado, una inocente seducida, pendencias, rencillas, enojos, burlada la justicia pública, aplaudido el engaño y celebrado por los espectadores» ${ }^{24}$.

23 A.H.N. 878-27.

24. Luis E. Sánchez García: «Iglesia y teatro en Córdoba a fines del siglo XVIII» Boletín de la Real Academia de Córdoba, n. ${ }^{\circ}$ 103, enero-diciembre 1982, pp. 167-192. 
La documentación del Consejo nos informa de que incluso en pueblos de corto vecindario se gustaba de representaciones, y las hubo, aunque fuera de forma intermitente durante la época de estímulo gubernamental, que fue muy corto, porque ya en 1782 , dos años antes de la prohibición general, se prohíben en Carcabuey, alegando como motivo que en los pueblos pequeños no se podían guardar las ordenanzas dictadas por Felipe $\mathrm{V}$ y se padecían escándalos y vicios ${ }^{25}$. En Lucena, población con título de ciudad y crecido vecindario, hubo un intento de resucitar las representaciones a fines del reinado de Carlos III, concretamente en 3 de julio de 1788, fecha de un memorial elevado por la cofradía de Nuestra Señora de la Paz. Pedía que «un coliseo contiguo a su ermita amenazando ruina» se habilitara para funciones públicas a su beneficio. A pesar del informe favorable del ayuntamiento, el Consejo de Castilla rechazó la petición basándose en la prohibición general de 1784 . Volvió a la carga la cofradía en 1792 alegando que «hace muchos años posee dicha finca, con cuyo producto ha subvenido al culto de Nuestra Señora. Que el motivo de haberse cerrado el patio de comedias fue porque el platero del Cabildo eclesiástico de Córdoba interesó al Ilmo. Sr. Justa Navarro para que ocurriese al Rey con el fin de que se prohibiesen las comedias en Lucena, dimanando todo de que un sobrino suyo representó en él en clase de cómico, sin que haya habido motivo particular de queja ni haya sucedido desgracia en más de dos siglos que ha estado corriente aquel coliseo». Agregaba que aquella población de veinte mil habitantes no tenía ninguna diversión que la apartase de «ruinosos y criminales pasatiempos» y le sirviera de lenitivo en su trabajo. Alegaba la revocación reciente que de la prohibición anterior se había hecho en favor de Málaga, Granada y Zaragoza, pero el fiscal insistió en la negativa porque «el producto de espectáculos profanos es un gravamen del pueblo y fruto de unas diversiones poco gratas a Dios y a sus santos» ${ }^{26}$, dictamen que confirma la falta de un criterio firme en cuanto a espectáculos públicos en las esferas gubernamentales. 
La casa de comedias de Málaga había sido construida por la hermandad que administraba el hospital de la caridad. Debió de ser un edificio suntuoso atendiendo a su costo de 34.000 ducados. Quizás debido a estas circunstancias se defendió más tiempo de la ofensiva general desencadenada por la Iglesia a fines del XVII contra el teatro. La petición del cabildo a Felipe V, hecha en 8 de enero de 1715, para que lo prohibiera, no tuvo consecuencia. La polémica siguió, con varias vicisitudes, hasta que en 1750 , aprovechando el clima emocional producido por una epidemia, el obispo Eulate consiguió su cierre, y además, para imposibilitar su reapertura, dispuso el derribo del edificio, indemnizando al hospital.

En 1764 llegó a Málaga Rafael Solis, «autor de cómicos», con un despacho que le autorizaba para dar representaciones; como no existía local se puso en contacto con Salvador Márquez, que comenzó la construcción de un teatro; cuando ya llevaba invertidos 25.000 reales en las obras, fueron paralizadas por orden de la ciudad, aduciendo el voto que había hecho de no admitir representaciones. La real cédula de 17 de junio de 1767 autorizando los espectáculos teatrales en todo el Reino a pesar de los votos y disposiciones en contrario, dio un nuevo giro a la situación. Márquez, alentado por vecinos acaudalados, continuó las obras del teatro. Parece que no era más que un maestro de albañilería, por lo que la obra no sólo salió defectuosa sino que se entrampó en fuertes cantidades, originando problemas y litigios ajenos al tema que aquí nos ocupa. Lo cierto es que había en Málaga un ambiente propicio, sobre todo en las autoridades civiles, y la prueba es que el propio gobernador, marqués de Villel, redactó un reglamento de comedias aprobado por el Consejo de Castilla por auto de 11 de diciembre de 1767, "con la calidad que reconocidas las comedias, entremeses y sainetes, y expurgados de cualesquiera cláusulas y expresiones mal sonantes que puedan causar ruina espiritual por letrados o sujetos instruidos y literatos, se dé el permiso por la justicia real ordinaria sin introducirse por ningún motivo el eclesiástico en estos asuntos [...] y para la quietud y formalidad de la concurrencia pedirá V.S. la asistencia de la tropa que juzgase necesaria». La huella del tándem Aranda- 
Campomanes se refleja muy clara en estas frases ${ }^{27}$. Las representaciones comenzaron el 3 de abril de 1768 y a pesar del forcejeo entre el ayuntamiento y Salvador Márquez en cuanto a la concentración de las compañías de comedias, continuaron hasta la $\mathbf{R}$. Orden de 16 de marzo de 1784, por la que el rey, «atendiendo a lo que han representado el Deán y Cabildo de la Santa Iglesia de Málaga» resolvió "que ahora ni en tiempo alguno, ni en dicha ciudad ni en alguno de los pueblos de su diócesis, se puedan representar comedias en teatros públicos destinados a este efecto, ni con el pretexto de ser por pocos días ni con otro alguno» ${ }^{28}$.

Ya en el reinado de Carlos IV las representaciones reaparecieron de forma un tanto subrepticia, según denunciaba Salvador Márquez en 1792: «estos pasados meses representó en aquella ciudad un extranjero llamado Pedro Lazcano, quien habiendo solicitado permiso para la diversión de títeres fue agregando la representación de algunos pasos de comedia y se extendió luego a dar escenas y aun actos, en un corralón incómodo situado en parte remota e indecente para tal ciudad». No contento con ello, Lazcano, aprovechando el levantamiento de la prohibición de comedias, ha formado compañía y ha pedido permiso para edificar teatro de nueva planta, lo que va contra la exclusiva concedida a Márquez; entre tanto ha formado compañía y da representaciones en un corralón a subidos precios. Por su parte, Márquez ofrecía, si se le mantenía en su privilegio, «hacer un nuevo coliseo de buena arquitectura, suficiente capacidad y en sitio de los más cómodos y proporcionados de Málaga» ${ }^{29}$. Al fin fue Lazcano, gracias a sus buenas relaciones, quien obtuvo el permiso de representar, no sin que de nuevo se manifestara la honda división que existía dentro del cabildo secular, donde una mayoría de capitulares seguía oponiéndose al restablecimiento del teatro. $\mathrm{Cu}$ -

27 A.H.N. Consejos, 1.239-6. El expediente consta de dos piezas y abunda en detalles curiosos y no aprovechados sobre la vida teatral malagueña: precios de las entradas, sueldos de los cómicos, etc. El primer galán ganaba 30 reales más 4 de ración al día. La compañia inicial la formaban 9 damas y 19 galanes, con un sueldo total de 542 reales diarios más 105 de raciones. Había también seis músicos. Id. id. 878-27.

Véanse los expedientes citados en las dos notas anteriores. 
rioso es el voto negativo que emitió el Síndico Procurador General, basado en que las bellezas de la ciudad hacían innecesarias otra clase de diversiones... «Y siendo cierto que en el cuerpo político no es menos arriesgado que en el humano, cuando logra una entera sanidad, pretender aumentarla con medicinas, me parece no carece de peligro el querer mejorar de suerte con novedades que de ningún modo necesita». Pese a todo, el nuevo coliseo se inauguró en $1793^{30}$.

En Granada el teatro atravesó los mismos avatares que en las demás capitales andaluzas. A pesar de las investigaciones de José M. ${ }^{a}$ Caparrós $^{31}$, Juan Sanz Sampelayo ${ }^{32}$ y Manuel Garzón Pareja ${ }^{33}$ quedan no pocos puntos oscuros por dilucidar. Tuvo un corral de hermosa fábrica inaugurado en 1593, y a comienzos del XVII la afición a estos espectáculos era tan grande que uno de los veinticuatro se refirió en sesión celebrada en 27 de febrero de 1604 a «los muy grandes inconvenientes que hay de haber muchas companías de actores", por lo que el concejo decidió que sólo se autorizaran las que tuviesen licencia real. Llegó después el declive, por las causas generales ya reseñadas, y sin llegarse a una prohibición absoluta, de hecho las representaciones estuvieron suspendidas largos años, unas veces por calamidades públicas, otras por la presión de las autoridades eclesiásticas, unánimes en su oposición, mientras que el cabildo secular cambió con frecuencia de criterio, cambios que se tradujeron en períodos de tolerancia y de prohibición. Los terremotos de noviembre de 1778 motivaron el voto del ayuntamiento de no permitir más representaciones «para aplacar la ira de Dios» y la confirmación real llegó con la R.O. de 15 de diciembre. No deja de ser sintomático que la pesada máquina burocrática funcionara con tal rapidez cuando se trataba de proscribir las comedias. «De nada sirvieron, dice Sanz Sampelayo, las protestas y súplicas de amplios

30 Siro Villas Tinoco: Málaga en tiempos de la revolución francesa, Universidad de Málaga, 1979, pp. 172-175.

31 «Prohibición de las comedias en Córdoba y Granada (siglo XVIII)», Revista del Centro de Estudios Históricos de Granada, año II, n. ${ }^{\circ}$ 2, pp. 118-124.

32 Granada en el siglo XVIII, Granada, Diputación Provincial, 1980, pp. 42 y sig.

33 Historia de Granada, II, 1981, Diputación Provincial de Granada, pp. 109-111. 
sectores de la población para que se, revocara tal decisión. El 30 de mayo de 1784 el arzobispo conseguía por una Real Orden ampliar la suspensión de representar comedias a todo el territorio de su jurisdicción, medida que respaldó el obispo de Guadix al solicitar de Madrid dicha suspensión también para su diócesis» ${ }^{34}$. Inmediatamente, el ayuntamiento daba marcha atrás, solicitaba de Madrid la revocación del voto y argüía en favor de las comedias que, desde que habían cesado, habían aumentado la prostitución y los juegos de azar. Pero los gobernantes madrileños, tan solícitos a atender la demanda de prohibición hecha por el arzobispo, se negaron a atender la del cabildo secular, lo que demuestra que la supremacía del poder civil tuvo también sus altibajos en la fase final del reinado de Carlos III. A duras penas se evitó que la casa de comedias se convirtiese en cárcel ${ }^{35}$.

José Szmolka, en una reciente historia de Jaén ${ }^{36}$, alude a la enemiga del clero y a la supresión del teatro en Jaén y en Andújar. Sólo puedo concretar que el ayuntamiento de la capital pidió confirmación del acuerdo tomado en mayo de 1780 de no permitir comedias. La confirmación real llegó en 6 de marzo siguiente por medio de una nota a Ventura Figueroa, presidente del consejo ${ }^{37}$. En Andújar existía casa de comedias desde el siglo XVII; en 18 de octubre de 1706 se leyeron en cabildo dos memoriales, uno del clero secular y otro de los conventos, solicitando que, en atención a los desastres que se padecían y siguiendo el ejemplo de otras ciudades andaluzas, se prohibiesen las representaciones. Los munícipes tomaron acuerdo en tal sentido, con voto solemne y perpetuo ${ }^{38}$. Sin embargo, como solía ocurrir, las ge-

Sanz Sampelayo, obra citada, p. 43. La misma súplica había hecho la ciudad de Loja, obteniendo R.O. confirmatoria en 31 de enero de 1784 (A.H.N. Consejos, 892-4).

35 Véase el expediente formado con motivo de la representación hecha por el diputado del Común en 29 de enero de 1779 sobre el destino que se había de dar a la Casa de Comedias en A.H.N. Consejos, 749-20. Sanz Sampelayo indica que el edificio se mantuvo y fue objeto de reformas en 1792, mientras que Garzón Pareja afirma que el edificio fue derruido, comenzándose en 1802 la fábrica del Teatro Principal que se terminó bajo la ocupación francesa por orden del mariscal Sebastiani.

36 Historia de Jaén por profesores de su Colegio Universitario, Jaén, Diputación Provincial, 1982, p. 384.

37 A.G.S. Gracia y Justicia, 993.

38 A.H.N. Consejos, 1.179-15. 
neraciones siguientes no se sentían ligadas por tales votos, y las comedias volvieron a representarse en fecha indeterminada, hasta que «las premoniciones de una monja trinitaria dieron al traste con el teatro, suspendiéndose las representaciones y destinándose en 1761 la casa de comedias a cuartel y, tras unos tímidos intentos por devolverla a su función específica, en 1788 a sede del ayuntamiento» ${ }^{39}$.

Esos «tímidos intentos» de que habla Szmolka deben referirse a los primeros años del reinado de Carlos III, pero el ayuntamiento se mantuvo en su actitud, pues habiéndose presentado en la ciudad el año 1771 el empresario Mariano de la Rosa con carta orden del presidente del consejo para que pudiera representar, el cabildo, aunque no se atrevió a impedírselo, escribió al conde de Aranda manifestándole que tenia hecho voto de no admitir comedias $^{40}$. El punto final fue la confirmación real al voto, hecha al mismo tiempo que a Jaén, Ronda y otras ciudades de Andalucía ${ }^{41}$.

Finalizamos estos apuntes, forzosamente incompletos, con un documento referente al teatro en Almería, ciudad que en el XVII quedó casi despoblada por la expulsión de los moriscos. El restablecimiento gradual que experimentó en el XVIII animó a algunas compañías ambulantes a incluirla en sus itinerarios; así, en 1732 el cabildo de su catedral pide al gobernador que no deje actuar «una farsa de comedias». El nuevo clima creado a partir de 1767 debió de reanimar la afición teatral; tenemos la prueba de ello en el permiso dado en 1767 por lá ciudad a D. Manuel Muñoz del Pino para edificar teatro «en el terreno que ocupaba la muralla antigua, situada en el interior del actual recinto». Núñez renunció porque el lugar señalado no reunía las condiciones necesarias, y entonces el diputado del Común, D. Antonio Antón, «dijo que no correspondía al lustre de esta ciudad que en las ocasiones que se presentan compañías de cómicos o que traen

\footnotetext{
39 J. Szmolka en la citada obra, p. 385.

40 Expdte citado en la nota 30.

41 Expdte citado en la nota 37.
} 
otras diversiones hayan de concurrir las justicias y nobleza a un sítio incómodo y expuestos a la inclemencia del tiempo, como se ha experimentado, siendo cierto que en otros pueblos de menos conveniencias hay casa de comedias». Ofrecía construir una en terrenos de su propiedad entre la playa de Castro y la Almedina, con tal de que no se permitieran en otro sitio comedias, volatines ni títeres. Con los informes favorables de la ciudad y el corregidor, el Consejo concedió la licencia, no sin expresar a la ciudad su desagrado por haberse comenzado las obras sin su permiso. La Real Cédula se expidió en 5 de noviembre de 1778.

Mal negocio hizo el diputado Antón, según él mismo expresó en memorial del año 1785, es decir, al año siguiente de la prohibición general de comedias en Andalucia: «Las resultas no han correspondido a sus deseos de afianzar alguna utilidad para su familia, porque en el largo tiempo transcurrido desde la construcción sólo cinco temporadas ha habido diversiones, y su producto tan escaso que apenas ha sacado para los gastos precisos». Nótese que habla, en general, de diversiones, lo que puede incluir espectáculos de títeres y volatines, o sea, acróbatas. Antón, medio arruinado, ofreció el edificio al municipio, que no quiso comprarlo, y finalmente, obtuvo permiso del Consejo para derribarlo ${ }^{42}$.

Querríamos agregar unas líneas a guisa de colofón de cuanto antecede. Dentro de este panorama variopinto hay un solo rasgo inmutable: la enemiga, si no de la Iglesia como institución, sí de la mayoría del clero contra los espectáculos teatrales. No es fácil explicar las raíces de una aversión tan profunda. En el terreno doctrinal nada podía achacarse al teatro de la época. Las declaraciones se basaban en los aspectos morales, ya en cuanto al espectáculo en sí, ya en cuanto a la conducta de los faranduleros. Este rigorismo moral y la convicción de que las catástrofes naturales (guerras, hambres, epidemias) eran castigos divinos por los peca-

42 A.H.N. Consejos, 697-18. 
dos fueron argumentos explotados a fondo por los eclesiásticos, sobre todo por los misioneros, y explican reacciones populares como la quema del teatro de Écija por las masas después de escuchar un sermón de misión.

A veces apuntan también los argumentos socioeconómicos: las clases medias gastan mucho dinero en los espectáculos y las bajas no sólo gastan lo que no tienen sino que abandonan los hábitos de trabajo. No hay separación clara entre estos argumentos y los de tipo religioso, aunque se advierte que los eclesiásticos insisten más en éstos y las autoridades municipales en aquéllos. En conjunto, se saca la impresión de que la Iglesia española se había quedado anclada en la época barroca, con toda su carga emocional, olvidada de su tradición intelectualista del Renacimiento. En el siglo XVI era dura con las desviaciones doctrinales e indulgente con las debilidades humanas. En el XVIII mantiene su rigidez doctrinal y la extiende a los aspectos morales. No cabe otra explicación para su obsesión antiteatral.

La actitud de la sociedad civil era mucho más variada. Encontramos posturas de sentido muy diverso, desde el rechazo total hasta la aceptación entusiasta. ¿Era el pueblo aficionado a los espectáculos? Para José M. ${ }^{\text {a }}$ Caparrós las prohibiciones no arrancaron de una raíz popular: «se nota en los documentos que tenemos a la vista como la masa del pueblo se resistía a abdicar de las representaciones [...] Por eso, no bien cesan las autoridades un instante en la persecución contra los comediantes, surgen por doquier aparatos y tablados, en los que asendereados cómicos de la legua explotan la sencilla curiosidad del pueblo» ${ }^{43}$. Por su parte, Martínez de Mazas, autor de un Retrato al natural de Jaén, escribía: «publíquese que hay un novillo de cuerda por las calles, una función de máscaras o un estrafalario saltimbanquis que llame la atención del pueblo, y al punto se cierran las tiendas y obradores; la gente más miserable deja inmediatamente su trabajo y todos salen a ver la novedad ${ }^{44}$. Esto es cierto. El pueblo 
en general tenía una gran apetencia de diversiones, precisamente porque escaseaban. Ésta era la tesis de Jovellanos, Forner y los ilustrados en conjunto. Pero también era cierto, y resulta de la documentación que hemos manejado, que si los cómicos eran acogidos al principio con entusiasmo, pronto los corrales se veían medio vacíos, por desinterés o por falta de medios para costear unas entradas que, a pesar de su módico precio, representaban una carga para la economía de la masa popular. Por eso el teatro sólo se representaba de manera permanente en poblaciones importantes, donde había una clase alta y media capaz de gustar de sus bellezas y soportar sus gastos.

La actitud de las autoridades también se presta a diversas consideraciones. Ya queda dicho que Carlos III no tenía en esta materia criterio propio; ausente de su espíritu toda preocupación de orden estético, sólo se le podía influir con motivaciones políticas o religiosas. Fueron las primeras las que pusieron en juego los hombres de su entorno, en especial Campomanes, para que autorizara e incluso alentara el restablecimiento del teatro, dejando sin efecto los votos y prohibiciones hechos con anterioridad. Pero aquel pequeño núcleo carecía de unidad. Aranda, Floridablanca, Campomanes y el confesor real, el franciscano Eleta, uno de los hombres más influyentes del reinado, sólo estaban de acuerdo en su odio a los jesuitas y discrepaban mucho en otros aspectos. Por eso, en cuanto quedó atrás la crisis desencadenada por los motines y resuelta con la expulsión de los jesuitas, aquel grupo se disgregó y Carlos III recobró su verdadera faz de hombre indeciso, devoto y en el fondo muy conservador. Uno de los aspectos en que se manifiesta mejor el cambio de rumbo es la actitud oficial ante el teatro. Los enemigos, que eran numerosos, que habían aceptado a regañadientes el restablecimiento de las comedias, intuyeron este cambio en la atmósfera de la Corte y reanudaron su ofensiva, acogida de muy buen grado por Eleta y por el acomodaticio abate Ventura Figueroa, sucesor de Aranda en la Presidencia de Castilla. Así se llegó a la serie de peticiones de los pueblos y ciudades contra el arte escénico que, con la aprobación real, barrieron las representaciones de toda Andalucia, excepto Cádiz, en 1784. Para mayor inri, era el propio Campo- 
manes el que tenía que transmitir a los municipios estas reales órdenes. Un político con un mínimum de dignidad personal hubiera dimitido; pero él tenía tanto horror a dejar su puesto como Carlos III a cambiar de personal gobernante, y gracias a esta abdicación moral obtuvo más tarde la presidencia de Castilla, desde la que practicó una política que, no sólo en éste sino en otros aspectos, desdecía de la que había proclamado y de sus convicciones íntimas.

En cuanto a los Ayuntamientos, formandos por una oligarquía de regidores perpetuos, también hemos podido darnos cuenta de sus vacilaciones, de sus contradicciones. Nunca hubo unanimidad en el seno de aquellas corporaciones, y a la diversidad de criterios se sumaba la influencia de elementos externos: pasajero interés por las normas dictadas en 1767, repliegue ante la ofensiva misional, seguida de una nueva racha de votos y prohibiciones. Finalmente, en los años finales del siglo, una atmósfera más abierta, más relajada dentro de la extremada variedad de comportamiento. Así, las actitudes ante el teatro venían a ser un espejo de los cambios experimentados por la sociedad española. 